\title{
Pursuing a germinal centre career
}

Antigen-primed B cells form germinal centres, where, helped by follicular helper $\mathrm{T}\left(\mathrm{T}_{\mathrm{FH}}\right)$ cells, they develop into high-affinity plasma and memory $\mathrm{B}$ cells. This process is under stringent control to avoid uncontrolled B cell proliferation and production of autoantibodies. Now, two studies published in Nature Medicine report that germinal centre reactions are controlled by regulatory $\mathrm{T}\left(\mathrm{T}_{\mathrm{Reg}}\right)$ cells with a $\mathrm{T}_{\mathrm{FH}}$ cell-like phenotype.

The two studies identified forkhead box P3 (FOXP3) ${ }^{+} \mathrm{T}_{\mathrm{Reg}}$ cells expressing the $\mathrm{T}_{\mathrm{FH}}$ cell-associated factors CXC-chemokine receptor 5 (CXCR5) and B cell lymphoma 6 (BCL-6) in the germinal centres of immunized mice. These follicular $\mathrm{T}_{\text {Reg }}$ cells expressed both $\mathrm{T}_{\mathrm{FH}}$ cellassociated and $\mathrm{T}_{\text {Reg }}$ cell-associated genes and were suppressive in vitro.

So, do follicular $\mathrm{T}_{\mathrm{Reg}}$ cells develop from $\mathrm{T}_{\mathrm{FH}}$ or $\mathrm{T}_{\mathrm{Reg}}$ cells? Adoptive transfer experiments indicated that follicular $\mathrm{T}_{\text {Reg }}$ cells originate from $\mathrm{T}_{\text {Reg }}$ cells. Moreover, Linterman et al. showed that thymus-derived but not induced $\mathrm{T}_{\mathrm{Reg}}$ cells are the follicular

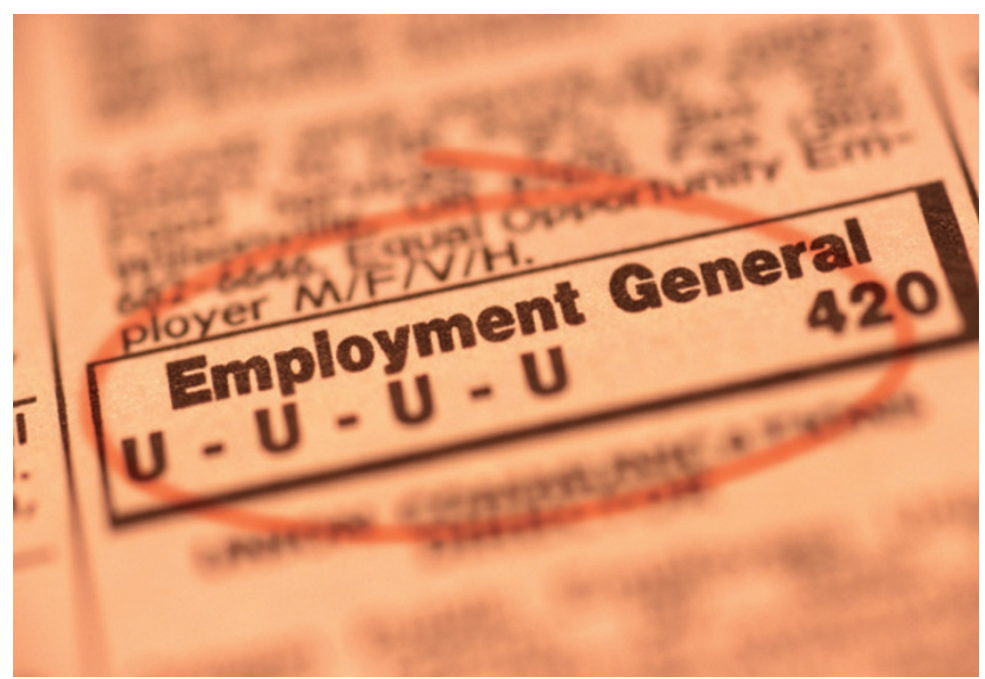

$\mathrm{T}_{\text {Reg }}$ cell progenitors. In addition, they observed that, similarly to $\mathrm{T}_{\mathrm{FH}}$ cells, follicular $\mathrm{T}_{\mathrm{Reg}}$ cells require signalling through CD28 and SLAM-associated protein (SAP) for their generation, and both studies demonstrated that BCL-6 expression is essential for their differentiation. Thus, BCL-6 expression and SAP-mediated signalling lead to the development of follicular $\mathrm{T}_{\text {Reg }}$ cells from natural $\mathrm{T}_{\text {Reg }}$ cells.

But what is the function of follicular $\mathrm{T}_{\mathrm{Reg}}$ cells? To address this, Linterman et al. generated chimeric mice that contained SAP-deficient $T$ cells (which cannot differentiate into $\mathrm{T}_{\mathrm{FH}}$ or follicular $\mathrm{T}_{\mathrm{Reg}}$ cells), as well as $T$ cells expressing the diphtheria toxin receptor under the control of the Foxp3 promoter. Selective depletion of follicular $\mathrm{T}_{\mathrm{Reg}}$ cells with diphtheria toxin resulted in increased numbers of $\mathrm{T}_{\mathrm{FH}}$ cells and germinal centre B cells in response to immunization. Intriguingly, the numbers of non-antigen-specific B cells were increased, whereas the percentages of antigen-specific plasma cells and memory B cells were reduced in chimeric mice lacking follicular $\mathrm{T}_{\text {Reg }}$ cells, compared with the numbers in control chimaeras. Thus, the authors suggest that follicular $\mathrm{T}_{\text {Reg }}$ cells limit $\mathrm{T}_{\mathrm{FH}}$ cell numbers, and possibly select against those that are self-reactive, thereby providing a competitive advantage to high-affinity antigen-specific B cells.

By contrast, Chung et al. observed no increase in $\mathrm{T}_{\mathrm{FH}}$ cell numbers in response to immunization when they transferred naive $\mathrm{CD} 4^{+}$ T cells together with BCL-6- or CXCR5-deficient $\mathrm{T}_{\text {Reg }}$ cells (which cannot differentiate into follicular $\mathrm{T}_{\text {Reg }}$ cells) into $\mathrm{T}$ cell-deficient recipients. In their model, the absence of follicular $\mathrm{T}_{\mathrm{Reg}}$ cells resulted in increased numbers of germinal centre B cells but also in elevated levels of antigen-specific B cells and high-affinity immunoglobulins.

Taken together, the two studies describe the BCL-6-dependent differentiation of natural $\mathrm{T}_{\text {Reg }}$ cells into follicular $\mathrm{T}_{\mathrm{Reg}}$ cells, which negatively regulate germinal centre $B$ cell numbers. The seemingly opposing conclusions on the effect of follicular $\mathrm{T}_{\mathrm{Reg}}$ cells on antigen-specific $\mathrm{B}$ cell responses may rely on the experimental approaches used, and further research will clarify the contribution of follicular $\mathrm{T}_{\text {Reg }}$ cells to the regulation of germinal centre reactions.

Maria Papatriantafyllou

ORIGINAL RESEARCH PAPERS Linterman, M. A. et al. Foxp $3^{+}$follicular regulatory T cells control the germinal center response. Nature Med. 17, 975-982 (2011) | Chung, Y. et al. Follicular regulatory T cells expressing Foxp3 and Bcl-6 suppress germinal center reactions. Nature Med. 17, 983-988 (2011)

FURTHER READING Campbell, D. J. \& Koch, M. A $T_{\text {reg }}$ cells: patrolling a dangerous neighborhood. Nature Med. 17, 929-930 (2011)|Campbell, D. J. \& Koch, M. A. Phenotypical and functional specialization of FOXP3 $3^{+}$regulatory T cells. Nature Rev. Immunol. 11, 119-130 (2011) 